\title{
Spatial-Temporal Characteristics of Past and Projected Climate Over Dairy Production Zones: A Case of Nandi County, Kenya
}

\author{
Josephine Wangechi Kirui $^{1 *}$ John Nzioka Muthama ${ }^{2} \quad$ Joshua Ndiwa Ngaina $^{3}$ \\ Charles Karuku Gachuiri ${ }^{4}$ \\ 1.Department of Meteorology, University of Nairobi, P.O Box 30197, 00100, Nairobi, Kenya \\ 2.Wangari Maathai Institute, University of Nairobi, P.O Box 30197, 00100, Nairobi, Kenya \\ 3.Department of Meteorology, South Eastern Kenya University, P.O Box 170, 90200, Kitui, Kenya \\ 4.Department of Animal Production, University of Nairobi, P.O Box 30197, 00100, Nairobi, Kenya
}

This research received no external funding.

\section{Abstract}

Climate change is regarded as a significant global environmental threat. This study assesses downscaled projections of climate change over dairy production regions (Nandi County) of Kenya using Rossby Centre Regional Atmospheric Model (RCA4) outputs driven by the eight (8) coordinated regional Downscaling Experiment (CORDEX) models. Climate baseline period (1971-2000) was used to evaluate CORDEX model performance against different sources of precipitation and temperature observations. Graphical and statistical approaches which correlation; Mann-Kendall test and nonparametric Sen's method were used to assess the trends in both past and future climate. Spatial analysis involved mapping of climate variables. Assessment of the skill of CORDEX models shows significant bias in the individual models in simulating precipitation. However, maximum and minimum temperatures performed well based on both individual and ensemble based outputs. CORDEX model outputs were comparable to observations, and either overestimated or underestimated the climate. Past and projected precipitation remains bimodal and highly variable (increasing/decreasing) in both space and time. Positive change between baseline and projected temperatures were noted for RCP45 and RCP85. As a response to the effects of climate variability and change, adoption of climate smart agricultural technologies is necessary to ensure that smallholder farmers put adequate measures to adapt and mitigate impact of climate change

Keywords: Precipitation; temperature; climate; projections; CORDEX

DOI: $10.7176 / \mathrm{JEES} / 10-6-06$

Publication date: June $30^{\text {th }} 2020$

\section{Introduction}

The earth surface's temperature has spiked continuously in the last 30 years more than any other preceding decade since 1850 , with the temperatures exhibiting considerable decadal and inter-annual variability, mostly attributable to greenhouse gas (GHG) emitted through human activities (IPCC, 2014). Societal interest to know the future changes in climate has been rising especially on climate change and variability including extreme events (Tebaldi, 2006). According to Trenberth and Fasullo (2012), future climate is expected to become more extreme. Consequently, the changes are likely to significantly impact negatively the livelihoods of populations especially in developing countries (Mertz et al., 2009). Based on IPCC AR5 (2013), global temperatures have been increasing between 1800 and 2012 at the rate of 0.65 to $\left.1.06^{\circ} \mathrm{C}\right)$. Similarly, several studies have noted that the global mean temperatures have been undergoing warming (Li et al., 2016; Su et al., 2016 and Xue et al., 2017) and precipitation changes that have significant impacts on the environment (Swain and Hayhoe, 2015). Consequently, it is projected that the observed changes in climate will continue into the future (Kharin et al., 2013). The trends of global warming show likelihood of an increase in $21^{\text {st }}$ Century by $0.3-1.7^{\circ} \mathrm{C}, 1.1-2.6^{\circ} \mathrm{C}, 1.4$ to $3.1^{\circ} \mathrm{C}, 2.6-4.8^{\circ} \mathrm{C}$ under RCP2.6, RCP4.5, RCP6.0, RCP8.5 for 2081-2100 period relative to 1986-2005 respectively (IPCC, 2013).

Climate variability and change ultimately impacts on the local seasonal and annual water-distribution, with a resulting negative effect on both agriculture and subsequent food productivity and security (Herrero et al., 2009). Countries already struggling with food security are likely to find themselves struggling harder in the future as climate change (CC) exerts significant impacts in all sectors of agriculture. There exists a relationship between climate change, agriculture and food security because climate change can directly affect a country's ability to feed its people. IPCC (2014) showed that Africa is at a high risk of experiencing climate change (Serdeczny et al., 2015) as it heavily depends on rain water for agriculture.

According to Hayhoe et al. (2017) and Girvetz et al. (2019), a common approach to project climate variability and change at global level is through the use of emission scenarios of Carbon Dioxide $\left(\mathrm{CO}_{2}\right)$ to drive the Global climate models (GCMs). The GCMs have been used to simulate atmospheric general circulation at continental scale especially in Africa for different socioeconomic applications such as Health, Agriculture and Water (Alley et al., 2007). However, the course resolution (usually at 100 to $500 \mathrm{~km}$ ) of the GCMs limits its applicability in cases where regional impact studies that require high resolution are concerned (Giorgi, 2019; Shongwe et al., 2011; Rummukainen, 2010). This is true especially over eastern Africa where the sub-grid scale variations which include 
vegetation, topography and soils significantly influence the climate (Endris et al., 2013). Further, policies geared towards climate change adaptation and mitigation requires information at fine spatial and temporal scales than those of GCM (Endris et al., 2013).

Downscaling of climate information has made it possible to provide climate outputs at finer scale and thus understand regional to local climate. At regional scale, assessment of the impacts of climate change based on high resolution projections has been made possible by Coordinated Regional Climate Downscaling Experiment (CORDEX) program initiated by the World Climate Research Program (WCRP) (Giorgi, 2019). Studies by Endris et al. (2013) Nikulin et al. (2012), Kisembe et al. (2019) and Ogega et al. (2020) that assessed the ability of CORDEX RCMs in simulating precipitation especially in East Africa noted that the main features of precipitation climatology were adequately captured. Although individual models showed significant bias, these individual models were outperformed by multimodel ensemble, an indicator that each model has its weaknesses and strength.

Understanding the impact of climate change on the livelihood of local communities and populations especially in Nandi County which remains highly heterogeneous requires sufficient quantification of projected changes in climate. Moreover, with majority of population being smallholder dairy farmers, adoption of climate smart agricultural technologies is dependent on robust and accessible climate change information.

\section{Materials and methods}

\subsection{Study area}

Kenyan highlands are characterized by highly intensive smallholder dairy production systems (Njarui et al. 2016). Despite the high population densities, majority of households are engaged in agricultural activities. Nandi County falls within the agro-ecological zones of Upper Highland (UH) to Upper Midland (UM) and is one of the major dairy zones in Kenya predominately smallholder farming that mainly relies on rain fed fodder production. The average farm size in the county has been reducing. It is expected that this land will reduce further because of the fast increase in population that causes land fragmentation (ASDSP. (2016). Major staple crops in the area include maize, millet, sorghum, and potatoes while pyrethrum, tea and coffee are main cash crops.

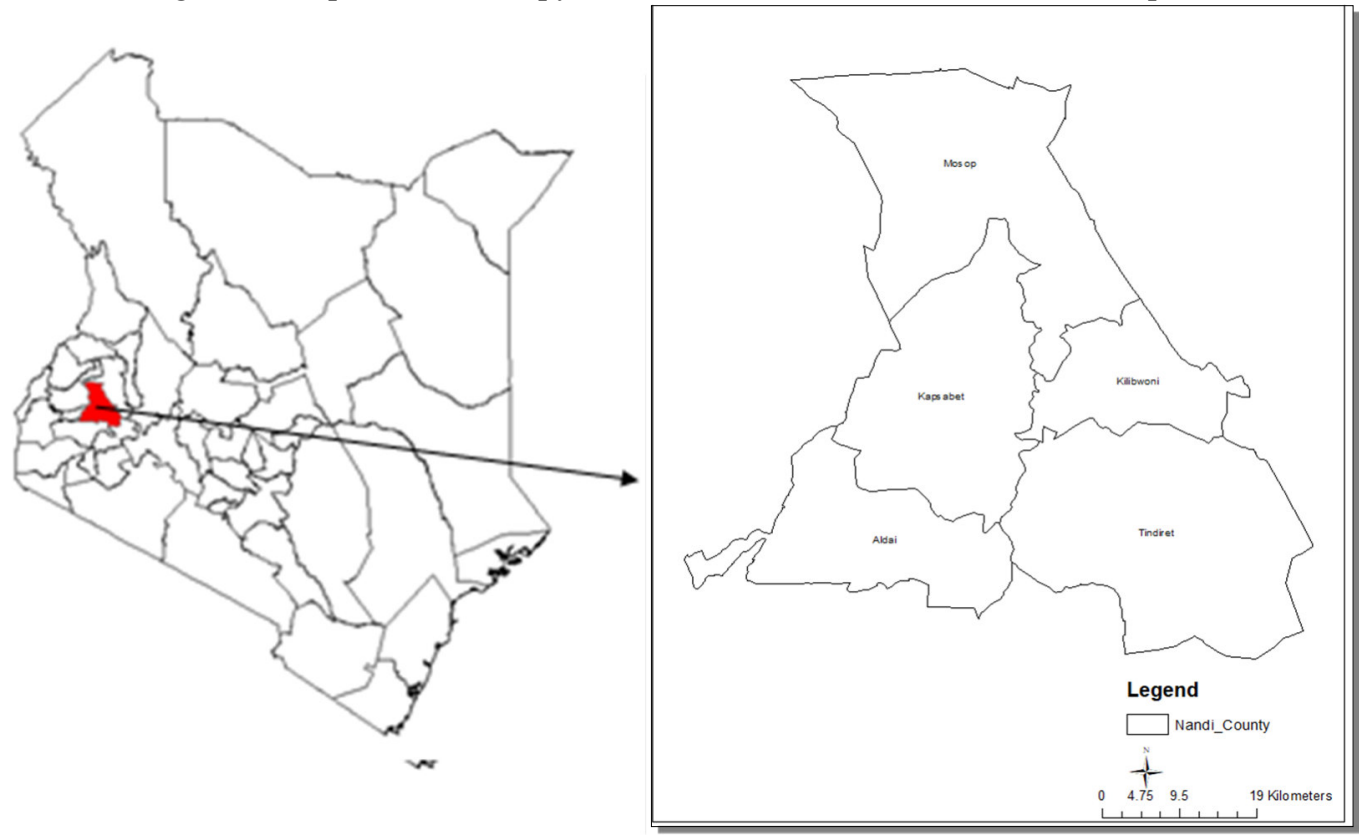

Figure 1: Map showing a) Kenya b) area of study (Nandi County)

\subsection{Data}

The data used in the study included both observed and model based climate datasets. Observed climate data were sourced from Kenya Meteorological department for stations located in Nandi County which included Nandi hills Tea estate and Kobujoi Forest station which were mainly rainfall stations. Data from Eldoret meteorological station was also collected. Due to limited availability of observational stations, the study utilized both satellite derived and assimilated climate variables. This included Climate Research Unit (CRU) precipitation datasets (Harris et al., 2020). The CRU precipitation datasets can originate station measurement using thin-plate splines interpolation with up to 14500 stations and provide precipitation data of all continents except Antarctica at resolution from the period 1901 to 2001. Climate model data which includes rainfall, maximum and minimum temperatures data were based on eight (8) CORDEX models downscaled by Rossby Centre Regional Atmospheric Model, (RCA4) run by Swedish meteorological and hydrological institute (SMHI) (Endris et al., 2013; Mukhala et al., 2017). The RCA4 
model is forced by lateral and surface boundary conditions from the European Centre for Medium-Range Weather Forecasts (ECMWF) Interim Re-Analysis (ERA-Interim). The baseline period considered for the study was 1971 to 2000 while the future period (projection) considered for the study was 2021 to 2050 . The future projections use Representative Concentration Pathways (RCPs) scenario 4.5WM $\mathrm{WM}^{2}$ (RCP45) and $8.5 \mathrm{WM}^{2}$ (RCP85). Detailed information of the CORDEX model outputs are provided by Nikulin et al. (2012)

\subsection{Research methodology}

The ability of the climate model to match the long-term historical climate observations was determined through both graphical (comparison of climatology) and statistical (correlation and Mean Absolute Error (MAE) analysis) approaches. The presence of a monotonic increasing or decreasing trend was tested with the nonparametric MannKendall test while the slope of a linear trend was estimated with the nonparametric Sen's method (Patakamuri et al. 2020). Furthermore, the true slope of the existing trend (as change per year) was estimated using the Sen's nonparametric method. The tested significance levels $\alpha$ were $0.001,0.01,0.05$ and 0.1 . For the four tested significance levels, the symbols used include *** $(\alpha=0.001), * *(\alpha=0.01), *(\alpha=0.05),+(\alpha=0.1)$ and $++(\alpha>$ 0.1 ). The true slope of an existing trend (as change per year) was estimated using the Sen's nonparametric method. The Sen Slope was then expressed as percent of the mean quantity per unit time as detailed in Salmi et al. (2002) and Slack et al. (2003). Geospatial information systems tools such as ARCGIS were used to determine spatial variability of both past and future climate through plotting of both seasonal (MAM, JJA, SON, and DJF) and annual maps.

\section{Results and discussion}

\subsection{Validation of CORDEX models in simulating climate over Nandi County}

Validation of CORDEX models in simulating climate over Nandi County was based on determination of its skill in simulating climatology and comparison of observed and CORDEX model outputs.

\subsubsection{Determination of the skill of CORDEX RCA4 model in simulating climatology}

Figure 2 (a) shows that Nandi County largely experienced bimodal rainfall distribution with peaks in April during the MAM season and October during the SON season. Further, it is noted that the climatology of observed and RCA4 model based results were comparable with differences between MAM and OND season attributed to the location of Inter Tropical Convergence Zone (ITCZ) in the vicinity of the equator during season. This is affirmed by numerous studies that have associated the bimodal rainfall regime over equatorial Africa to the passage the ITCZ, that sweeps the greater East Africa region twice annually (Omondi et al. 2012; Gitau et al., 2015; Omondi et al., 2015 and Wakachala et al., 2015). The study show that CORDEX RCA4 models underestimated observed rainfall during MAM season and overestimated rainfall during OND season. According to Panitz et al. (2014), regional climate models (RCMs) driven by GCMs inherits biases through the lateral boundary conditions that are added to those of the RCM limiting the ability of downscaling to improve the simulation skills of large-scale forcing while other cases may involve substantial difference of RCM climate change signal to that of the driving GCM (Dosio and Panitz, 2016). Omondi et al. (2015) noted that such dissimilarities may arise from different schemes employed in the individual models that are not able to capture the local circulation systems especially in the western parts of the country. The Figure 2 (b) showed that maximum temperatures peaked in February and September October. Noticeably, an ensemble of all the RCA4 models was comparable to the observed maximum temperature. During MAM and OND, the region receives the highest temperatures compared to JJA which receives the lowest temperatures. Similarly, Figure 2 (c) showed that minimum temperatures peaked in February and September. However, all the CORDEX RCA4 models were noted to overestimate the observed minimum temperature. The spatial distributions of maximum and minimum temperature are attributed to the apparent seasonal movement and position of the sun (Omondi et al., 2015) 
a)
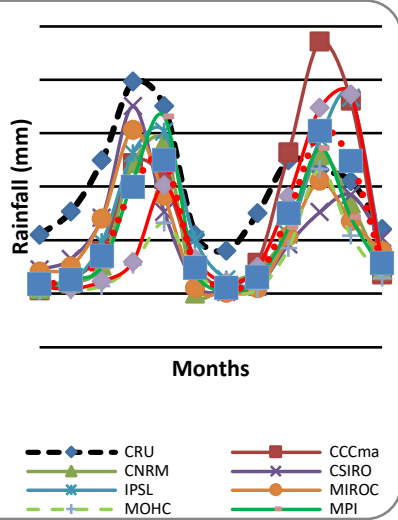

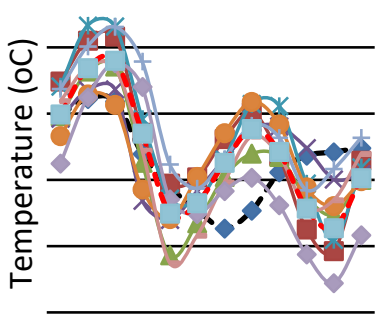

Months

b)

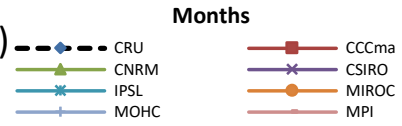

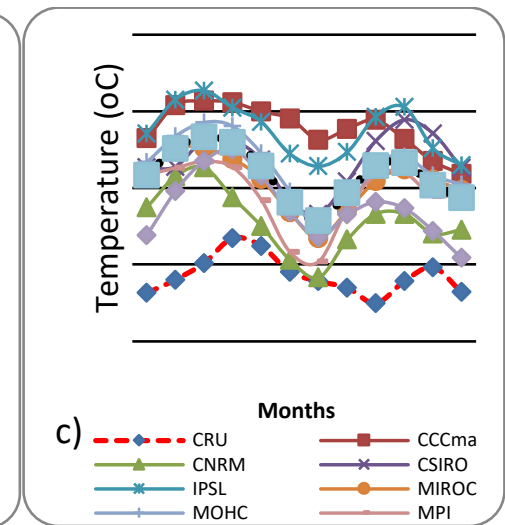

Figure 2: Climatology based on a) precipitation, b) maximum and c) minimum temperature over Nandi County (1971-2000).

\subsubsection{Comparison of observed and CORDEX model outputs over Nandi County}

In Table 1, correlation analysis indicates that CNRM and ICHEC models had the highest correlation while MOHC and NOAA had the lowest correlation with observed rainfall. Similarly, the models with highest correlation coefficient showed the lowest MAE i.e. 89.79 and 83.4 and thus the best performing models whereas the ensemble of all models had a MAE of 100.84. The low correlation coefficient values for rainfall could be attributed to its high spatiotemporal variability. The highest correlation coefficient for maximum temperature was noted in MOHC with a value of 0.58 whereas the lowest correlation coefficient in MIROC with a value of 0.16 . Further, MOHC model had the lowest MAE. For minimum temperatures, an Ensemble of all the models showed the highest correlation compared to individual models whereas models with highest correlation coefficients showed lower MAE values. Ideally, ensemble of all models is expected to perform better than individual models. However, for the case of Nandi County, the study noted that individual models performed better than ensemble of the RCA4 driven CORDEX models in simulating precipitation and maximum temperature while the ensemble of all the models performed well in simulating and minimum temperature.

Table 1: Error analysis between observed (CRU) and Model output

\begin{tabular}{|l|l|l|l|l|l|l|}
\hline \multirow{2}{*}{ Model } & \multicolumn{4}{|l|}{ Rainfall } & TMAX & \multicolumn{2}{l|}{ TMIN } \\
\cline { 2 - 7 } & Correlation & MAE & Correlation & MAE & Correlation & MAE \\
\hline CCCma & 0.12 & 94.17 & 0.41 & 1.82 & 0.31 & 3.79 \\
\hline CNRM & 0.21 & 89.79 & 0.51 & 1.39 & 0.22 & 1.51 \\
\hline CSIRO & 0.15 & 91.58 & 0.43 & 1.35 & 0.24 & 2.93 \\
\hline ICHEC & 0.21 & 83.48 & 0.48 & 1.25 & 0.18 & 2.56 \\
\hline IPSL & 0.20 & 90.91 & 0.45 & 1.98 & 0.32 & 1.37 \\
\hline MIROC & 0.17 & 86.68 & 0.16 & 1.80 & 0.21 & 3.76 \\
\hline MOHC & 0.10 & 90.03 & 0.58 & 1.64 & 0.38 & 2.35 \\
\hline MPI & 0.20 & 102.90 & 0.54 & 1.55 & 0.18 & 2.76 \\
\hline NOAA & -0.10 & 100.84 & 0.27 & 1.81 & 0.29 & 2.76 \\
\hline ENS & 0.18 & 100.84 & 0.52 & 1.81 & 0.40 & 2.76 \\
\hline
\end{tabular}

Note: ENS means Ensemble of all the 8 downscaled GCM models

\subsection{Temporal analysis of past climate}

Temporal analysis was based on both graphical and statistical analysis of the trend of past climate

\subsubsection{Graphical analysis of the trend of past climate}

The Figure 3 (a) showed that rainfall over Kobujoi station has been decreasing between 1971 and 2012. However, the coefficient of determination indicated that only $19.28 \%$ of data could be fitted along the line of best fit. Over Nandi hills tea estate (Figure 3 (b), the graph showed that rainfall had been increasing between 1971 and 2012. However, the coefficient of determination indicated that only $10.35 \%$ of data could be fitted along the line of best fit. An aerial average based on CRU (Figure 3 (c) indicated that rainfall had been decreasing over Nandi County. Compared to the nearest synoptic station located in Eldoret (Figure 3 (d)) showed that rainfall had been increasing with only $2.6 \%$ of the data fitted along the line of best fit. The varied results prove that rainfall remains highly variable even at small spatial and temporal scale. This necessitates the need to have more rainfall observation stations within the county. Moreover, it was noted that none of the stations within Nandi County were being observed at synoptic times. The Figure 4 (a) and Figure 5 (a) shows that maximum and minimum temperatures over Nandi based on CRU dataset for the period 1971-2015 had been increasing with $\mathrm{R}^{2}$ indicating that $66.38 \%$ and $68.26 \%$ of data could be fitted within the line of best fit respectively. Similarly patterns of increasing maximum 
(Figure $4 \mathrm{~b}$ ) and minimum (Figure $5 \mathrm{~b}$ ) temperatures were observed in Eldoret. However, the $\mathrm{R}^{2}$ indicated that only $7.7 \%$ and $25.3 \%$ for maximum and minimum temperatures could be fitted in the line of best fit. In general, both maximum and minimum temperatures have shown increasing trend within Nandi County. This is consistent with studies by Ongoma et al. (2013) and Wakachala et al. (2015).

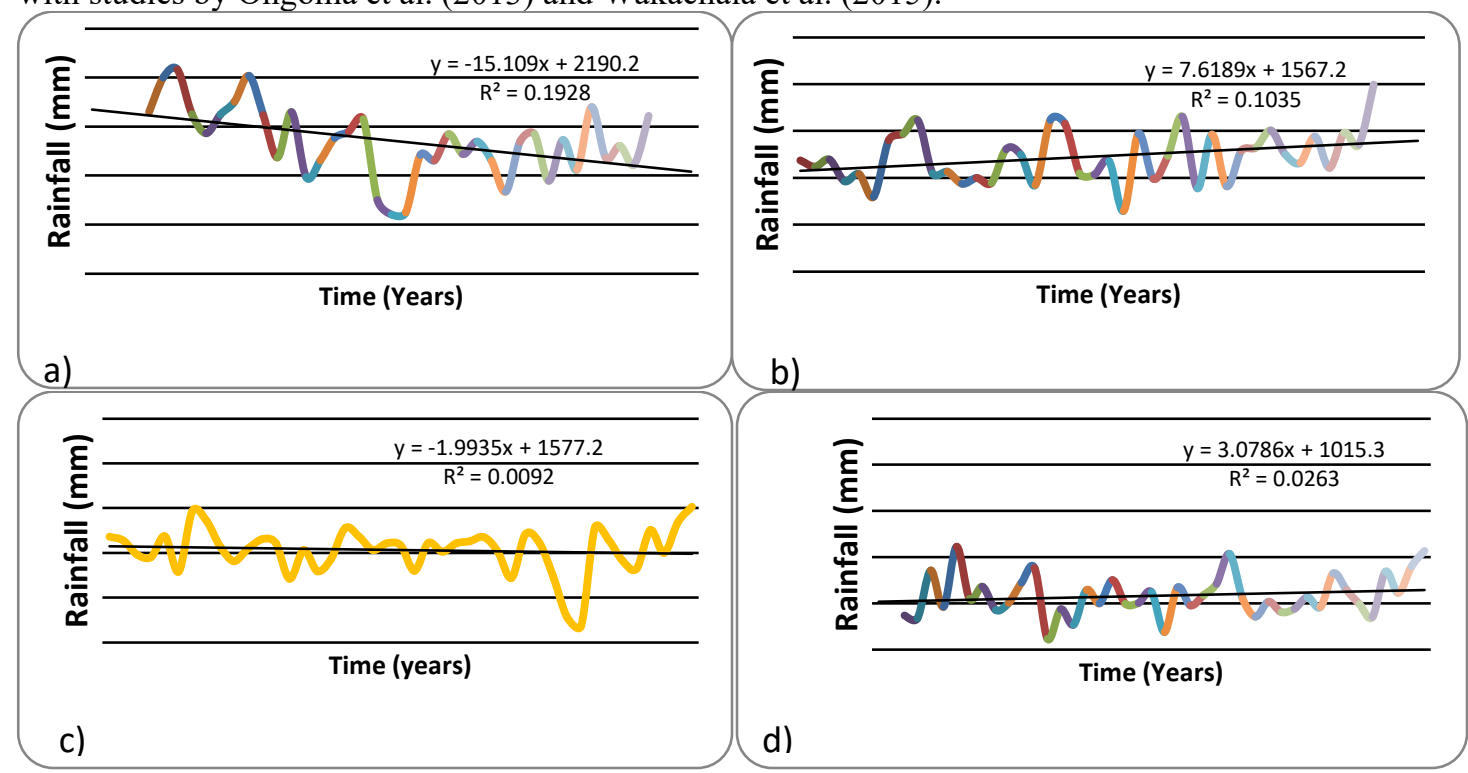

Figure 3: Graphical analysis of the trend of observed rainfall based on a) Kobujoi FS b) Nandi Hills TE, c) CRU and d) Eldoret stations

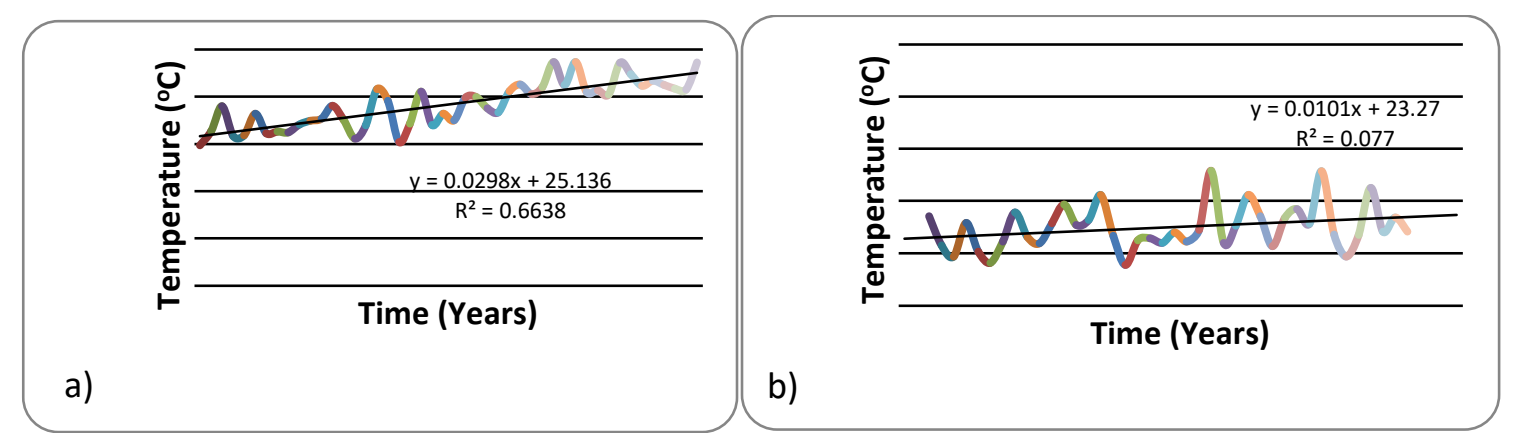

Figure 4: Graphical analysis of the trend of observed maximum temperature based on a) CRU-Nandi and b) Eldoret Station.

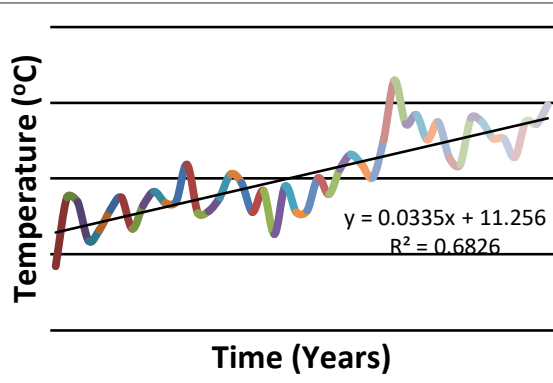

a)

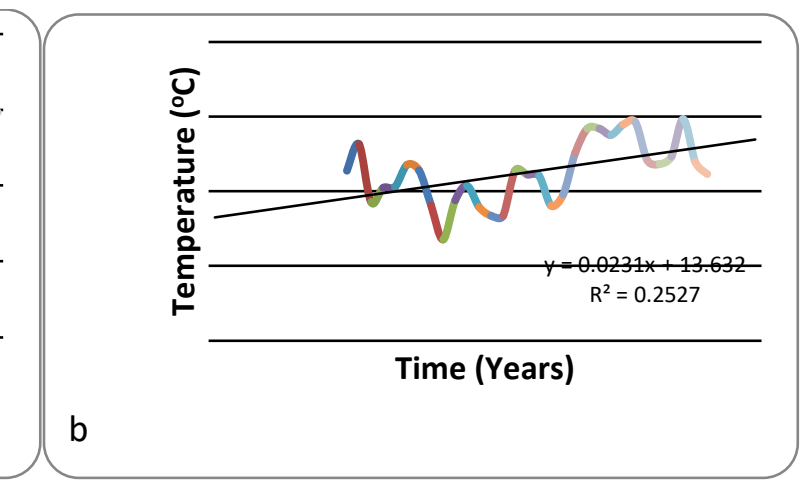

Figure 5: Graphical analysis of the trend of observed minimum temperature over a) CRU Nandi County and b) Eldoret station

\subsubsection{Statistical analysis of the trend of past climate}

Statistical analysis of the trend (Table 2) of past precipitation based rain gauge stations, RCA4 model output and CRU datasets indicate that seasonal (MAM, JJA, SON, DJF) and annual precipitation were either increasing or decreasing. However, these changes were noted to be significant at levels ranging between 0.05 and $>0.1$. Further, computed percentage change based on an ensemble of RCA4 models, CRU, and Eldoret stations datasets were all 
centered on $10 \%$. However, datasets from Nandi Hills and Kobujoi displayed largest percentage changes of up to $-54.7 \%$.

The observe variability could be attributed to the fact that data collections at Nandi Hills and Kobujoi stations mainly volunteer observers who may have limited training on required data collection. The trend of seasonal (MAM, JJA, SON, DJF) and annual maximum and minimum temperature based on ensemble of CORDEX RCA4 models and CRU were increasing with corresponding percentage change noted to be all positive at varied significant levels ranging between 0.05 and 0.1 . Notably, changes based on ensemble of CORDEX RCA4 models were noted to be lower compared to CRU

Table 2: Trend statistics of past climate (1971-2000) over Nandi County

\begin{tabular}{|c|c|c|c|c|c|c|c|c|c|c|}
\hline \multirow[t]{2}{*}{ Period } & \multirow[t]{2}{*}{ Stats } & \multicolumn{5}{|c|}{ Precipitation } & \multicolumn{2}{|c|}{$\begin{array}{l}\text { Maximum } \\
\text { temperature }\end{array}$} & \multicolumn{2}{|c|}{$\begin{array}{l}\text { Minimum } \\
\text { temperature }\end{array}$} \\
\hline & & ENS & $\mathrm{CRU}$ & Nandi Hills & Kobujoi & Eldoret & ENS & CRU & ENS & $\mathrm{CRU}$ \\
\hline \multirow[t]{2}{*}{ ANN } & $\mathrm{Z}$ & 1.0 & -0.8 & -0.6 & -2.0 & 0.3 & 3.0 & 3.6 & 3.85 & 3.18 \\
\hline & $\%$ & 6.7 & -5.0 & -6.6 & -49.6 & 7.5 & 1.4 & 3.0 & 3.81 & 5.23 \\
\hline \multirow[t]{2}{*}{ DJF } & $\mathrm{Z}$ & 0.0 & -0.2 & -1.4 & -1.5 & 0.2 & 2.2 & 2.3 & 3.03 & 1.14 \\
\hline & $\%$ & 0.4 & -9.3 & -19.6 & -32.2 & 9.4 & 1.5 & 3.1 & 2.98 & 2.47 \\
\hline \multirow[t]{2}{*}{ JJA } & $\mathrm{Z}$ & -1.4 & -1.7 & -0.6 & -1.9 & 0.1 & 3.0 & 3.5 & 3.43 & 2.93 \\
\hline & $\%$ & -12.6 & -17.5 & -8.4 & -54.7 & 3.5 & 1.9 & 3.8 & 5.25 & 9.35 \\
\hline \multirow[t]{2}{*}{ MAM } & $\mathrm{Z}$ & 0.5 & -0.2 & 0.4 & -1.8 & -0.3 & 1.0 & 1.5 & 3.28 & 2.21 \\
\hline & $\%$ & 8.1 & -3.8 & 4.7 & -33.5 & -9.0 & 1.0 & 2.1 & 3.39 & 6.20 \\
\hline \multirow[t]{2}{*}{ SON } & $\mathrm{Z}$ & 1.6 & 0.7 & 0.9 & -1.0 & 1.8 & 1.6 & 2.9 & 3.96 & 3.16 \\
\hline & $\%$ & 10.8 & 13.9 & 17.8 & -29.3 & 43.6 & 1.1 & 2.6 & 3.71 & 7.51 \\
\hline
\end{tabular}

\subsection{Spatial variability of past climate over Nandi County}

There exists noticeable differences between CRU (Figure 6) and ensemble of RCA4 based model output (Figure 7) in representing precipitation especially for JJA season. Seasonal and annual precipitation decreases from SW towards NE in CRU and vice versa in RCA4 based model outputs. For both CRU and ensemble of RCA based model outputs indicated maximum precipitation of up to $100 \mathrm{~mm}, 300 \mathrm{~mm}$ and $150 \mathrm{~mm}$ during DJF, MAM and Annual respectively whereas JJA and SON showed noticeable differences between the two datasets. The study noted that precipitation was highly variable in space over Nandi County. The study attributed the high spatial differences in precipitation datasets to course datasets used from both CORDEX and CRU in relation to Nandi County which is very small. The Figure 8 shows that maximum temperatures based on CRU were higher in the SW compared to the NE parts of Nandi County with values ranging between $22^{\circ} \mathrm{C}$ and $28^{\circ} \mathrm{C}$. Spatial analysis based on RCA4 models ensemble (Figure 9) show similar pattern of maximum temperatures with low values of $26^{\circ} \mathrm{C}$ and high of $36^{\circ} \mathrm{C}$. This meant that the RCA4 model ensemble values were slightly higher than those observed from CRU dataset. Similarly, a comparison of Figure 10 and Figure 11 show that minimum temperatures were higher in RCA4 based output compared to CRU. The minimum temperatures were up to a maximum of $28^{\circ} \mathrm{C}$.
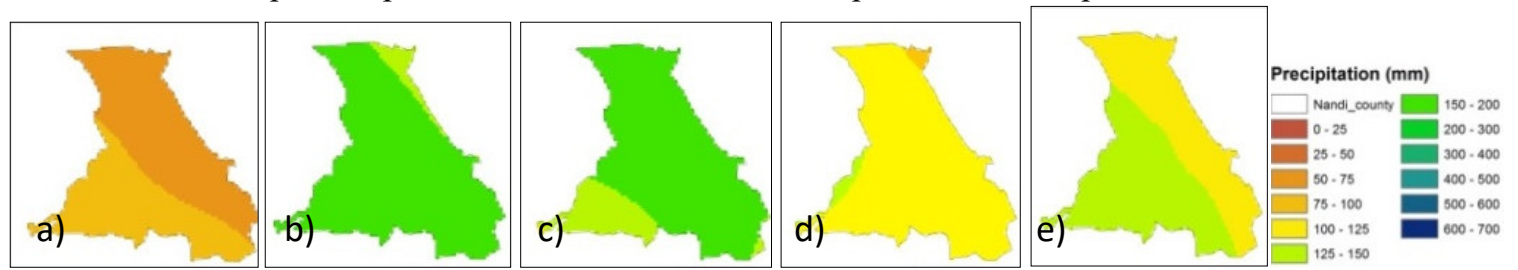

Figure 6: Spatial variability of past a) DJF b) MAM c) JJA d) SON and e) ANN rainfall based CRU over Nandi County
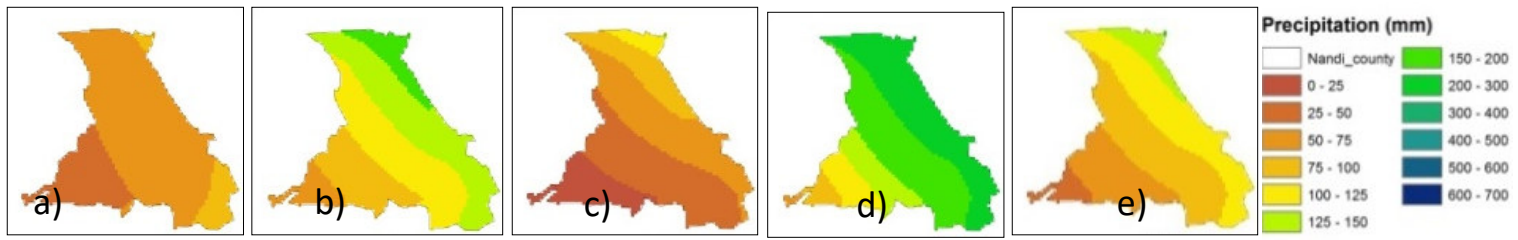

Figure 7: Spatial variability of past a) DJF b) MAM c) JJA d) SON and e) ANN rainfall based on ensemble of RCA4 models over Nandi County 

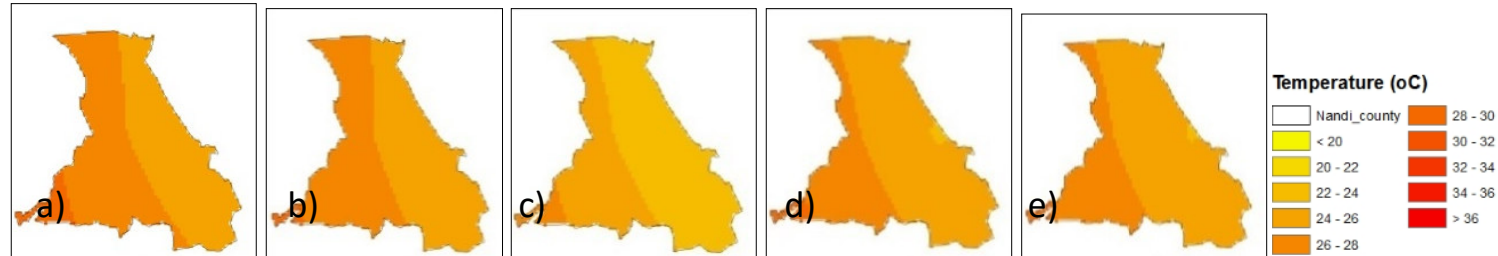

Figure 8: Spatial variability of past a) DJF b) MAM c) JJA d) SON and e) ANN maximum temperature based on CRU over Nandi County
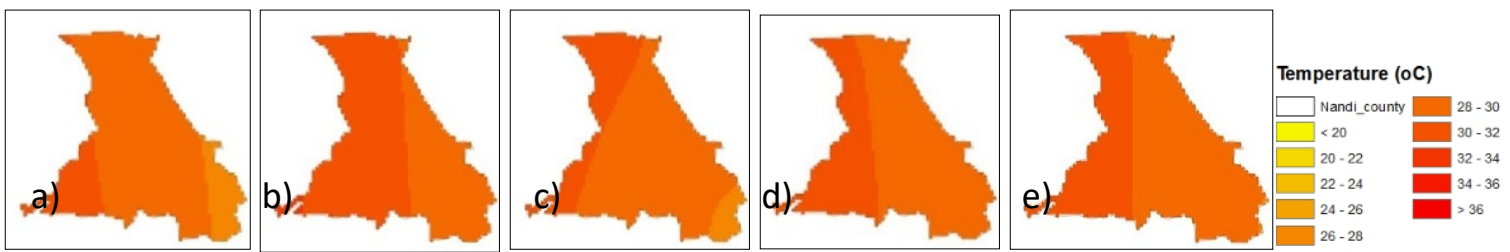

Figure 9: Spatial variability of past a) DJF b) MAM c) JJA d) SON and e) ANN maximum temperature based on RCA4 ensemble over Nandi County
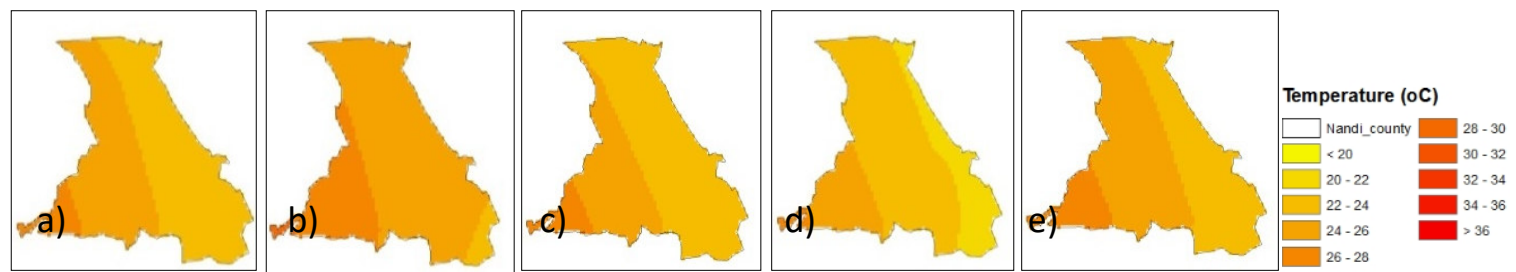

Figure 10: Spatial variability of past a) DJF b) MAM c) JJA d) SON and e) ANN minimum temperature based on CRU over Nandi County
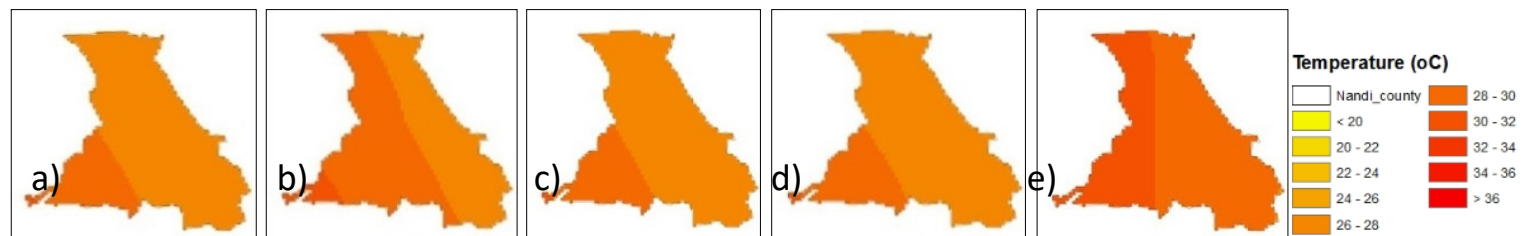

Figure 11: Spatial variability of past a) DJF b) MAM c) JJA d) SON and e) ANN minimum temperature based on RCA4 ensemble over Nandi County

\subsection{Temporal variability of future climate over Nandi County}

Temporal analysis was based on both graphical and statistical analysis of the trend of future climate

\subsubsection{Graphical analysis of the trend of future climate}

Graphical analysis of the trend of projected rainfall under RCP45 for the period 2021-2050 (Figure 12 a) show slight decrease in rainfall whereas projected rainfall trend under RCP85 for the period 2021-2050 (Figure $12 \mathrm{~b}$ ) show a steady increase in rainfall. Further analyses based on $\mathrm{R}^{2}$ show that $<1 \%$ for RCP 45 and $<12 \%$ for RCP85 of all the data could be fitted into the line of best fit. Graphical analysis of the trend of projected maximum temperature under both RCP45 (Figure 13 a) and RCP85 (Figure $13 \mathrm{~b}$ ) for the period 2021-2050 show a steady increase in temperatures. Analyses based on $\mathrm{R}^{2}$ show that up to $76 \%$ and $91.4 \%$ of datasets under RCP45 and RCP85 respectively could be fitted along the line of best fit making these trends very significant. Similarly, analyses of trend of projected minimum temperatures under both RCP45 (Figure $14 \mathrm{a}$ ) and RCP85 (Figure $14 \mathrm{~b}$ ) for the period 2021-2050 show a steady increase in temperatures. Analyses based on $\mathrm{R}^{2}$ show that up to $83.1 \%$ and $94.8 \%$ of datasets under RCP45 and RCP 85 respectively could be fitted along the line of best fit making these trends very significant 
a)
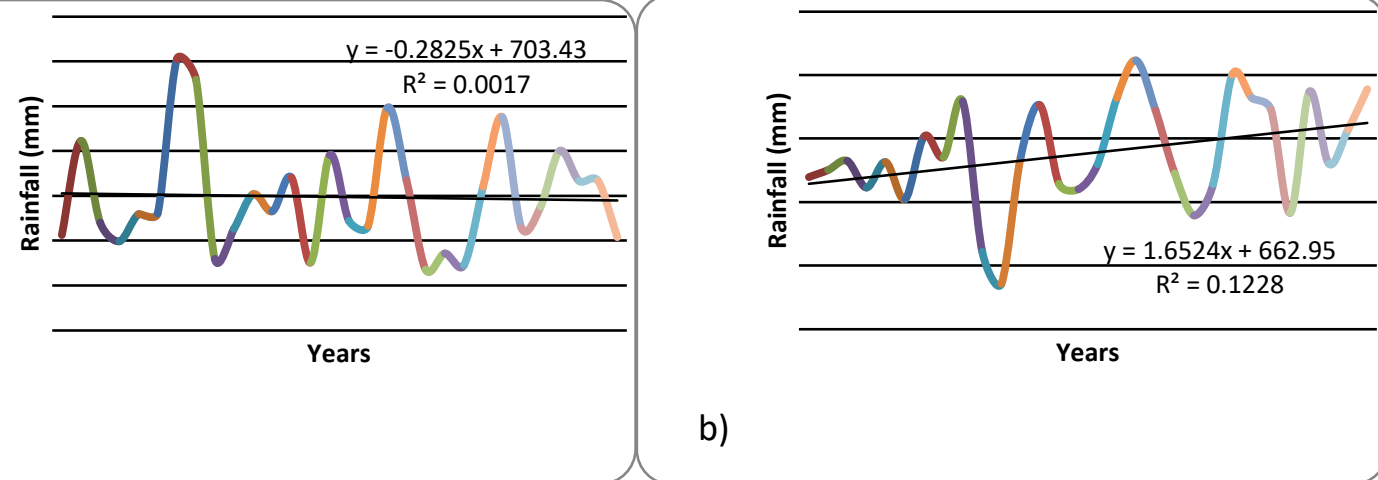

b)

Figure 12: Graphical analysis of the trend of future rainfall under a) RCP45 and b) RCP85 over Nandi County

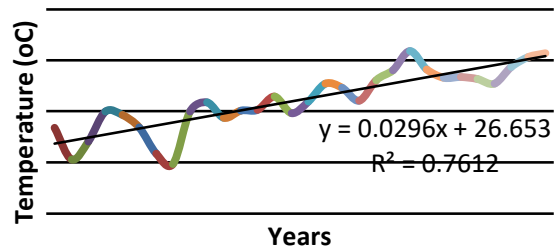

a)

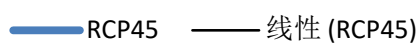

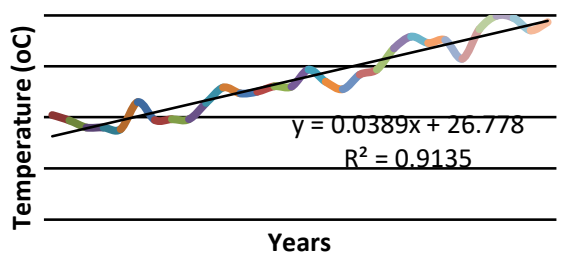

b)

Figure 13: Graphical analysis of the trend of future maximum temperature under a) RCP45 and b) RCP85 over Nandi County

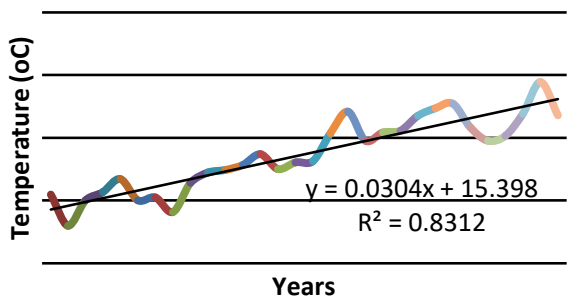

a)

$$
\text { RCP45 一 线性 (RCP45) }
$$

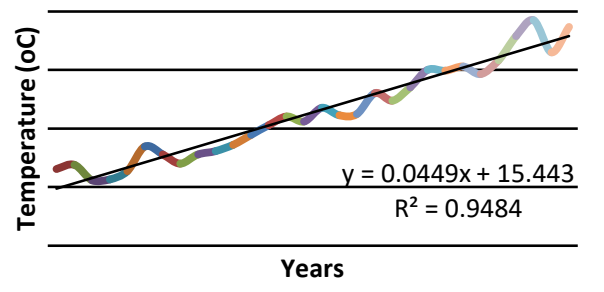

b) RCP85 — 线性 (RCP85)

Figure 14: Graphical analysis of the trend of minimum temperature under a) RCP45 and b) RCP85 over Nandi County

3.4.2. Statistical analysis of the trend of future climate over Nandi County

Statistical analysis of the trend (Table 3) based on seasonal (SON, MAM, JJA, DJF) and annual projected precipitation indicated either positive or negative change at significance level varying between 0.05 and 0.1 for both RCP45 and RCP85. Based on RCP45 changes ranged between -2.7 and 0.5 and were positive during annual, DJF and SON while other seasons displayed negative changes whereas based on RCP85 changes ranged between -0.3 and 1.8 and were positive during annual, DJF, MAM and SON while other seasons displayed negative changes. Further, annual percentage change based on RCP45 ranged between $-32.1 \%$ and $11.4 \%$ whereas changes under RCP85 ranged between $-1.4 \%$ and $26.7 \%$. Comparison of computed change between baseline and projected precipitation showed change of under both RCP45 to range between $-19.5 \%$ and $11.0 \%$ and between $-9.5 \%$ and $26.3 \%$ under RCP85. These findings indicate that projected seasonal and annual precipitations are expected to continue to display the high temporal variability under both RCP45 and RCP85. Statistical analysis of the trend (Table 3) based on seasonal (SON, MAM, JJA, DJF) and annual projected maximum temperature indicated positive (upward) change at the 0.001 significance level for both RCP45 and RCP85. The changes under RCP45 which ranged between 3.68 and 5.67 with its annual percentage change ranging between $2.77 \%$ and $4.12 \%$ whereas changes under RCP85 ranged between 5.2 and 7.3 with its annual percentage change ranging between $3.60 \%$ and $5.77 \%$. Comparison of computed change between baseline and projected maximum temperature showed positive change of under both RCP45 (between 1.31\% and 2.22\%) and RCP85 (between 1.8\% and 2.6\%). These findings indicate that seasonal and annual maximum temperatures are expected to continue increasing and at a faster rate 
under RCP85 compared to RCP45.Similarly, Statistical analysis of the trend (Table 3) based on seasonal (SON, MAM, JJA, DJF) and annual projected minimum temperature indicated positive (upward) change at the 0.001 significance level for both RCP45 and RCP85. The changes under RCP45 which ranged between 6.2 and 7.0 with its annual percentage change ranging between $7.5 \%$ and $10.8 \%$ whereas changes under RCP85 ranged between 4.5 and 6.4 with its annual percentage change ranging between $3.60 \%$ and $5.77 \%$. Comparison of computed change between baseline and projected minimum temperature showed positive change of under both RCP45 (between $3.9 \%$ and 5.5\%) and RCP85 (between $2.14 \%$ and 3.86\%). These findings indicate that seasonal and annual minimum temperatures are expected to continue increasing and at a faster rate under RCP45 compared to RCP85. Table 3: Trend statistics of projected rainfall (2021-2050) over Nandi County

\begin{tabular}{|l|l|l|l|l|l|l|l|}
\hline \multirow{3}{*}{ Variable } & Stats & Precipitation & Precipitation & \multicolumn{2}{l|}{ Maximum temperature } & \multicolumn{2}{l|}{ Minimum temperature } \\
\cline { 2 - 8 } & & RCP45 & RCP85 & RCP45 & RCP85 & RCP45 & RCP85 \\
\hline \multirow{5}{*}{ ANN } & $\mathrm{Z}$ & 0.1 & 1.8 & 5.67 & 5.9 & 7.0 & 6.32 \\
\cline { 2 - 8 } & $\%$ & 1.5 & 6.7 & 3.04 & 5.9 & 8.3 & 4.28 \\
\cline { 2 - 8 } & $\Delta \%$ & -5.3 & 0.0 & 1.67 & 2.1 & 4.5 & 2.91 \\
\hline \multirow{5}{*}{ DJF } & $\mathrm{Z}$ & 0.5 & 1.8 & 4.39 & 5.2 & 6.2 & 5.39 \\
\cline { 2 - 8 } & $\%$ & 11.4 & 26.7 & 2.77 & 5.5 & 7.6 & 3.60 \\
\cline { 2 - 8 } & $\Delta \%$ & 11.0 & 26.3 & 1.31 & 2.6 & 4.7 & 2.14 \\
\hline \multirow{5}{*}{ JJA } & $\mathrm{Z}$ & -2.7 & 0.3 & 5.53 & 5.1 & 6.5 & 6.39 \\
& $\%$ & -32.1 & 2.4 & 4.12 & 7.3 & 10.8 & 5.77 \\
\cline { 2 - 8 } & $\Delta \%$ & -19.5 & 15.0 & 2.22 & 2.1 & 5.5 & 3.86 \\
\hline \multirow{5}{*}{ MAM } & $\mathrm{Z}$ & -0.3 & -0.3 & 3.75 & 4.7 & 6.2 & 4.89 \\
\cline { 2 - 8 } & $\%$ & -1.6 & -1.4 & 2.99 & 5.2 & 7.5 & 4.16 \\
\cline { 2 - 8 } & $\Delta \%$ & -9.7 & -9.5 & 1.99 & 1.8 & 4.1 & 3.15 \\
\hline \multirow{3}{*}{ SON } & $\mathrm{Z}$ & 0.1 & 1.5 & 3.68 & 5.4 & 6.3 & 4.53 \\
\cline { 2 - 8 } & $\%$ & 0.7 & 9.4 & 2.31 & 5.4 & 7.6 & 4.17 \\
\cline { 2 - 8 } & $\Delta \%$ & -10.1 & -1.5 & 1.7 & 3.9 & 3.03 \\
\hline
\end{tabular}

\subsection{Spatial variability of projected climate over Nandi County}

Generally, precipitation distribution based on an ensemble of RCA4 models showed a SW to NE increase under both RCP45 (Figure 15) and RCP85 (Figure 16). Notably, the study indicated high spatial variability in both seasonal and annual rainfall over Nandi County with SON/JJA season expected to receive highest/lowest amounts of precipitation. Seasonal and annual projected maximum and minimum temperatures were decreasing from west to east under both RCP45 (Figure 17 and Figure 19) and RCP85 (Figure 18 and Figure 20). The study indicated that MAM season had the highest maximum and minimum temperatures with highest maximum and minimum temperatures noted under RCP45 compared to RCP85.

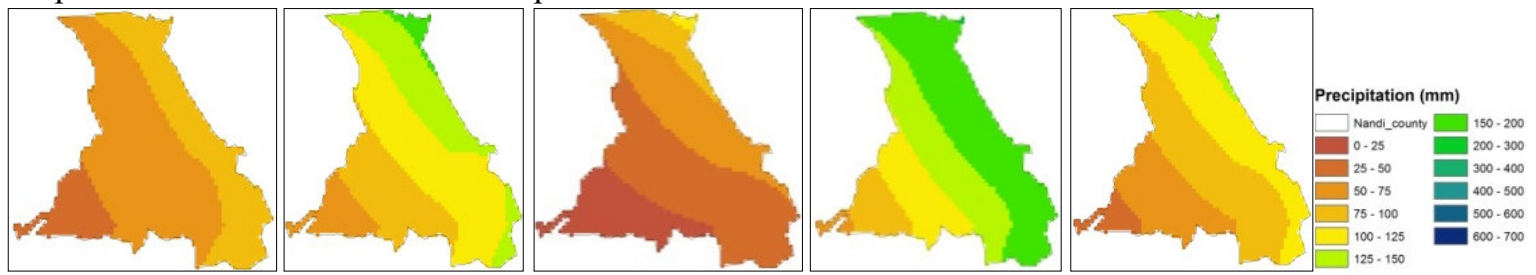

Figure 15: Spatial variability of projected a) DJF b) MAM c) JJA d) SON and e) ANN rainfall based on ensemble RCA4 models over Nandi County under RCP45
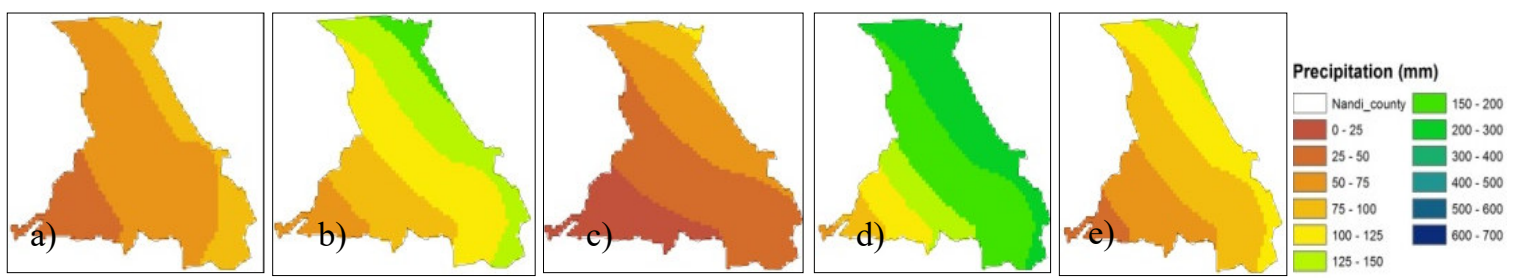

Figure 16: Spatial variability of projected a) DJF b) MAM c) JJA d) SON and e) ANN rainfall based on ensemble RCA4 models over Nandi County under RCP85 

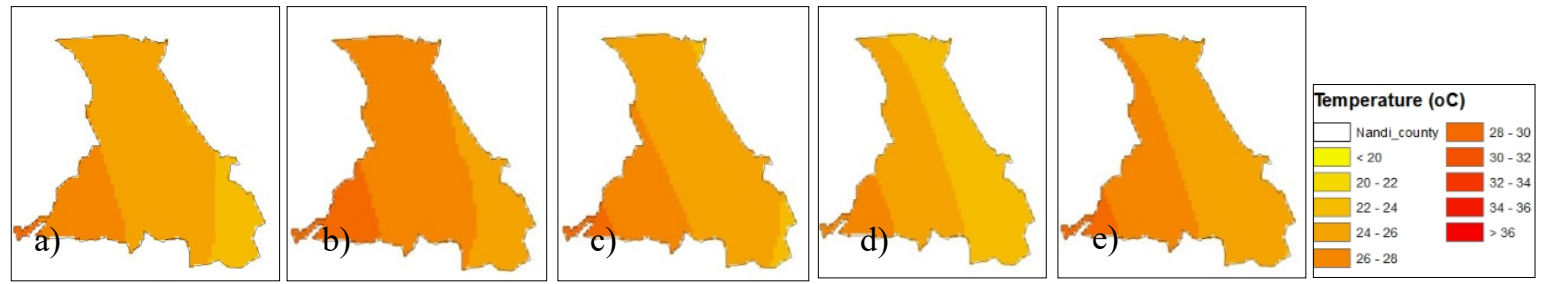

Figure 17: Spatial distribution of projected maximum temperature based on an ensemble of RCA4 models under RCP45 for a) DJF b) MAM c) JJA d) SON and e) ANN over Nandi County
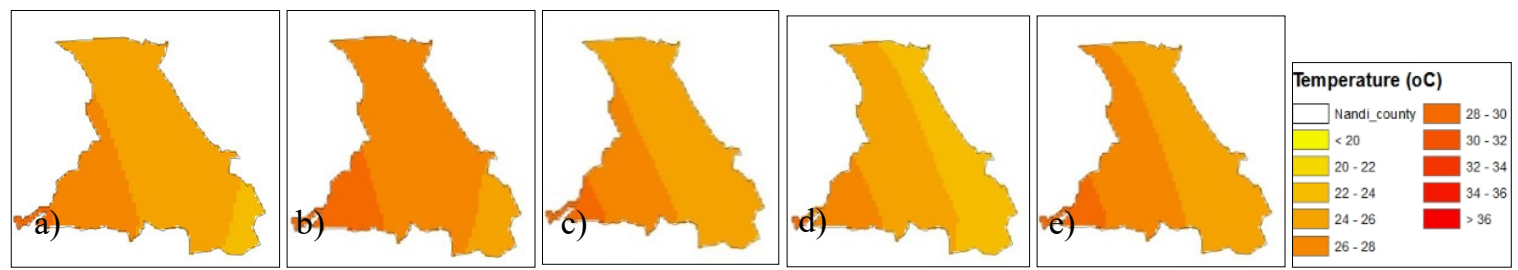

Figure 18: Spatial distribution of projected maximum temperature based on an ensemble of RCA4 models under RCP85 for a) DJF b) MAM c) JJA d) SON and e) ANN over Nandi County
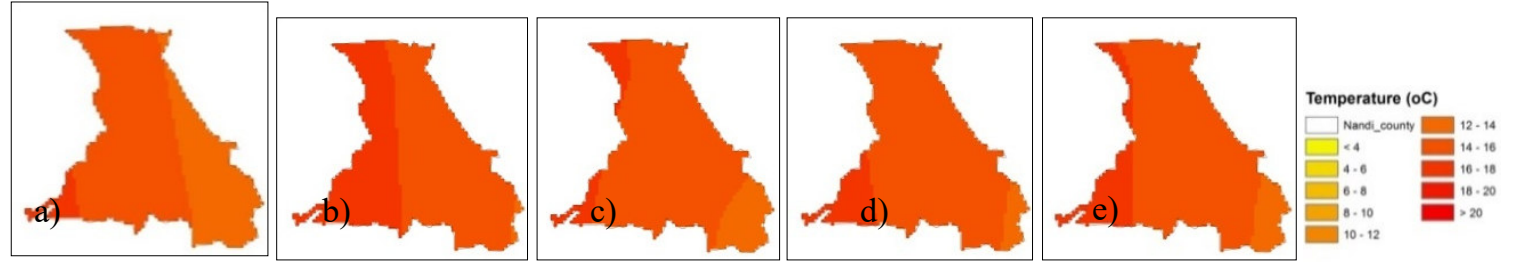

Figure19: Spatial distribution of projected minimum temperature based on an ensemble of RCA4 models under RCP45 for a) DJF b) MAM c) JJA d) SON and e) ANN over Nandi County
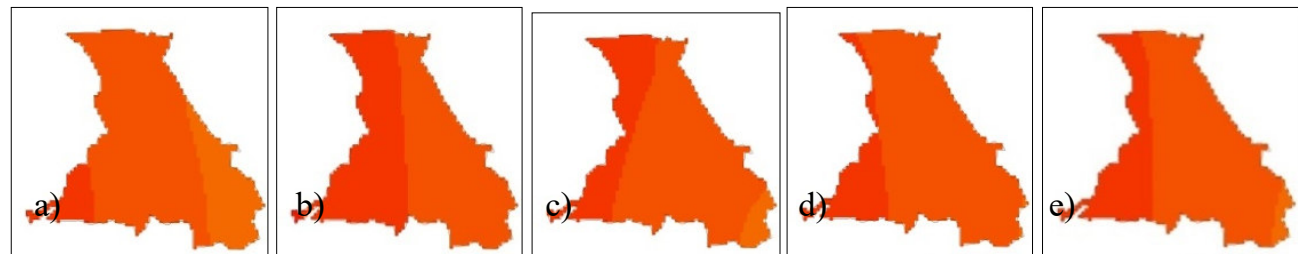

Temperature (oC)

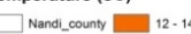

Figure 20: Spatial distribution of projected minimum temperature based on an ensemble of RCA4 models under RCP85 for a) DJF b) MAM c) JJA d) SON and e) ANN over Nandi County

\section{Conclusion and recommendation}

Assessment of the skill of CORDEX models show that individual models performed better than ensemble based outputs in simulating precipitation. However, maximum and minimum temperatures performed well based on both individual and ensemble based outputs. CORDEX model outputs were comparable to observations, and either overestimated or underestimated the climate. Past and projected precipitation remains bimodal and highly variable (increasing/decreasing) in both space and time. Computed percentage change for seasonal and annual precipitation was centered on $10 \%$ for baseline, $-32.1 \%$ to $11.4 \%$ for RCP 45 and $-1.4 \%$ to $26.7 \%$ for RCP 85 . Differences between baseline and projected precipitation were noted for RCP45 $(-19.5 \%$ to $11.0 \%)$ and RCP85 $(-9.5 \%$ and $26.3 \%$ ). Generally, precipitation distribution showed a SW to NE increase with SON/JJA season expected to receive highest/lowest amounts of precipitation. Analysis of projected maximum and minimum temperatures showed increasing trends. Computed percentage change for seasonal and annual maximum temperatures ranged between $1.0 \%$ and $3.8 \%$ for baseline, $2.77 \%$ and $4.12 \%$ for RCP45 and $3.60 \%$ and $5.77 \%$ for RCP 85 . Positive change were reported between baseline and projected maximum temperatures for RCP45 (between $1.31 \%$ and $2.22 \%$ ) and RCP85 (between 1.8\% and 2.6\%). Computed percentage change for seasonal and annual minimum temperatures ranged between $2.47 \%$ and $9.35 \%$ for baseline, $7.5 \%$ to $10.8 \%$ for RCP45 and $3.60 \%$ to $5.77 \%$ for RCP85. Positive change between baseline and projected minimum temperatures were noted for RCP45 (between $3.9 \%$ and $5.5 \%$ ) and RCP85 (between $2.14 \%$ and $3.86 \%$ ) and decreasing from west to east. MAM season had the highest maximum and minimum temperatures with higher temperatures noted for RCP45 compared to RCP85. As a response to the effects of climate variability and change, adoption of climate smart agricultural technologies is necessary to ensure that smallholder farmers put adequate measures to adapt and mitigate impact of climate change. 


\section{Author Contributions:}

All Authors were instrumental in conceptualization, methodological design, data analysis, interpretations, editing and formatting.

Acknowledgments: This paper is part of the $\mathrm{PhD}$ thesis presented to the University of Nairobi by the Lead Author. The authors would like to thank Kenya Meteorology Department, Climate Research Unit (CRU) of the University of East Anglia, and Coordinated Regional Downscaling Experiment (CORDEX) Africa for climate data and the team comprised of dairy farmers, farmer organization and Ministry of Agriculture and Livestock in Nandi County, Kenya for their support in data collection

Conflicts of Interest: The authors declare no conflict of interest.

\section{References}

ASDSP. (2016). Nandi County. Nairobi, Kenya

Endris HS, Omondi P, Jain S, Lennard C, Hewitson B, Changa L, Awange JL, Dosio A, Ketiem P, Nikulin G, Panitz HJ, Büchner M, Stordal F, Tazalika L (2013). Assessment of the performance of CORDEX regional climate models in simulating East African precipitation. J Clim 26:8453-8475.

https://doi.org/10.1175/JCLI-D-12-00708.1

Dosio A, Panitz H-J (2016) Climate change projections for CORDEX-Africa with COSMO-CLM regional climate model and differences with the driving global climate models. Clim Dyn 46(5-6):1599-1625. https://doi.org/10.1007/s00382-015-2664-4

Harris, I., Osborn, T.J., Jones, P. et al. Version 4 of the CRU TS monthly high-resolution gridded multivariate climate dataset. Sci Data 7, 109 (2020). https://doi.org/10.1038/s41597-020-0453-3

Hayhoe, K., J. Edmonds, R.E. Kopp, A.N. LeGrande, B.M. Sanderson, M.F. Wehner, and D.J. Wuebbles, 2017 : Climate models, scenarios, and projections. In: Climate Science Special Report: Fourth National Climate Assessment, Volume I [Wuebbles, D.J., D.W. Fahey, K.A. Hibbard, D.J. Dokken, B.C. Stewart, and T.K. Maycock (eds.)]. U.S. Global Change Research Program, Washington, DC, USA, pp. 133-160, doi: 10.7930/J0WH2N54.

Herrero, M., K, T. P., A, N., Msangi, S., S, W., Kruska, R., et al. (2009). Drivers of change in crop-livestock systems ecosystems services and human well-being to 2030

Giorgi, F. (2019). Thirty years of regional climate modeling: Where are we and where are we going next? Journal of Geophysical Research: Atmospheres, 124, 5696- 5723.

Girvetz E. et al. (2019) Future Climate Projections in Africa: Where Are We Headed?. In: Rosenstock T., Nowak A., Girvetz E. (eds) The Climate-Smart Agriculture Papers. Springer, Cham

Gitau, W., Camberlin, P., Ogallo, L., \& Okoola, R. 2. (2015). Oceanic and atmospheric linkages with short rainfall season intraseasonal statistics over Equatorial Eastern Africa and their predictive potential. International J. Climatol. , 35(5): 2382-2399

IPCC (2013). Climate Change 2013: The Physical Science Basis. Contribution of Working Group I to the Fifth Assessment Report of the Intergovernmental Panel on Climate Change [Stocker, T.F., D. Qin, G.-K. Plattner, M. Tignor, S.K. Allen, J. Boschung, A. Nauels, Y. Xia, V. Bex and P.M. Midgley (eds.)]. Cambridge University Press, Cambridge, United Kingdom and New York, NY, USA

IPCC (2014). Climate Change 2014. Synthesis Report. Contribution of Working Groups I,II and III to the Fifth Assessment Report .

Kharin, V.V., Zwiers, F.W., Zhang, X. et al. Changes in temperature and precipitation extremes in the CMIP5 ensemble. Climatic Change 119, 345-357 (2013). https://doi.org/10.1007/s10584-013-0705-8

Li Z et al 2016 Aerosol and monsoon climate interactions over Asia Rev. Geophys. 54 866-929

Mertz, O., Mbow, C., Reenberg, A. (2009). Farmers' Perceptions of Climate Change and Agricultural Adaptation Strategies in Rural Sahel. Environmental Management 43, 804-816. https://doi.org/10.1007/s00267-0089197-0

Mukhala, E., Ngaina, J.N., and Maingi, N.W. (2017) Downscaled Climate Analysis on Historical , Current and Future Trends in the East African Community Region. Nairobi, Kenya, 1-57

Njarui D M G, Gichangi E M, Gatheru M, Nyambati E M, Ondiko C N, Njunie M N, Ndungu-Magiroi K W, Kiiya W W, Kute C A O and Ayako W 2016 A comparative analysis of livestock farming in smallholder mixed crop-livestock systems in Kenya: 1. Livestock inventory and management. Livestock Research for Rural Development, Volume 28.

Nikulin G, Jones C, Giorgi F, Asrar G, Büchner M, Cerezo-Mota R, Christensen OB, Déqué M, Fernandez J, Hänsler A, van Meijgaard E, Samuelsson P, Sylla MB, Sushama L (2012) Precipitation climatology in an ensemble of CORDEX-Africa regional climate simulations. J Clim 25:6057-6078.

https://doi.org/10.1175/jcli-d-11-00375.1

Panitz, H., Dosio, A., Büchner, M., Luthi, D., \& Keuler, K. (2014). COSMO CLM (CCLM) climate simulations over CORDEX-Africa domain: analysis of the ERA-Interim driven simulations at $0.44^{\circ}$ and $0.22^{\circ}$ resolution. 
Clim Dyn , 42 (11-12):3015-3038.

Patakamuri, S.K.; Muthiah, K.; Sridhar, V. (2020). Long-Term Homogeneity, Trend, and Change-Point Analysis of Rainfall in the Arid District of Ananthapuramu, Andhra Pradesh State, India. Water, 12, 211.

Ogega, O.M., Koske, J., Kung'u, J.B. et al. Heavy precipitation events over East Africa in a changing Rummukainen, M., 2010: State-of-the-art with regional climate model. Wiley Interdiscip. Rev.: Climate Change, 1, 82-96, doi:10.1002/wcc.8

Omondi, P., Awange, J., Ogallo, L., Okoola, R., \& Forootan, E. (2012). Decadal rainfall variability modes in observed rainfall records over East Africa and their relations to historical sea surface temperature changes. $J$. Hydrolog , 464:140-156.

Omondi, M. H., Opijah, F., \& Ogallo, L. (2015). Assessment of temperature and precipitation extremes over Kenya using the coordinated regional downscaling experiment model outputs. Nairobu: University of Nairobi.

Ongoma, V., Muthama, J., \& Gitau, W. (2013). Evaluation of urbanization influences on urban temperature of Nairobi City, Kenya. Global Meteorology, 2(1): 1-5

Serdeczny, O., Adams, S., Baarsch, F., Coumou, D., Robinson, A., Hare, W., et al. (2015). Climate change impacts in Sub-Saharan Africa: from physical changes to their social repercussions. Springer: Environ Change, pp. 96-115

Shongwe ME, van Oldenborgh GJ, van den Hurk B, van Aalst M (2011) Projected changes in mean and extreme precipitation in Africa under global warming. Part II: East Africa. J Clim 24(14):3718-3733. https://doi.org/10.1175/2010JCLI2883.1

Swain, S. and K. Hayhoe, 2015: CMIP5 projected changes in spring and summer drought and 18 wet conditions over North America. Climate Dynamics, 44, 2737-2750. 19

http://dx.doi.org/10.1007/s00382-014-2255-9

Tebaldi C, Hayhoe K, Arblaster JM, Meehl GA. (2006). Going to the extremes: an intercomparison of modelsimulated historical and future changes in extreme events. Climatic Change 79: 185-211. DOI:10.1007/s10584-006-9051-4

Trenberth, K. E., and J. T. Fasullo, 2012: Climate extremes and climate change: The Russian Heat Wave and other Climate Extremes of 2010. J. Geophys. Res., 117, D17103, doi: 10.1029/2012JD018020

Kisembe, J., Favre, A., Dosio, A. et al. Evaluation of rainfall simulations over Uganda in CORDEX regional climate models. Theor Appl Climatol 137, 1117-1134 (2019). https://doi.org/10.1007/s00704-018-2643-X

climate: results from CORDEX RCMs. Clim Dyn (2020). https://doi.org/10.1007/s00382-020-05309-z

Wakachala, F., Z.W, S., Nguyo, J., Shaka, S., \& Apondo, W. (2015). Statistical Patterns of Rainfall Variability in the Great Rift Valley of Kenya . Journal of Environmental and Agricultural Sciences (ISSN: 2313-8629), $5: 17-26$ 